\title{
Preparing for a Career in Aquatic Animal Medicine ${ }^{1}$
}

Ruth Francis-Floyd, DVM, MS, Dipl. ACZM²

At the University of Florida we receive many inquiries from high school and college students interested in pursuing a career in aquatic animal medicine. We commonly get requests for suggestions for course work and other preparations and questions about career options. Before we can make suggestions, it is important that the student articulate his or her career goals as clearly as possible. There are quite a few career paths available, and many more are likely to be created in the coming years. Key considerations for students include an honest personal assessment of interests, talents, and academic ability. If the goal is to be an aquatic animal veterinarian, then obviously the first step is to put together a competitive packet for admission to a college of veterinary medicine. There are also many career opportunities that do not require a veterinary degree.

Some suggestions for these career options and how to prepare for them are offered below.

\section{Careers that May not Require Formal Education Beyond the Bachelor's Degree}

Careers with aquatic animals that do not require academic training beyond a bachelor's degree include laboratory technician, aquaculture technician, veterinary technician, aquarist or zoo keeper. Many of these careers are hands-on jobs that are directly involved with daily animal care or handling. A general education in biology or a related field is often good academic preparation. Some of these positions may only require a two-year degree. For example, Santa Fe Community College (Gainesville, FL) offers a two-year degree for zoo keepers and Hillsborough Community College (Tampa, FL) offers a two-year degree for aquaculture technicians. There are also two-year programs that provide certification for veterinary and laboratory technicians. Experience is also very important in developing a competitive resume. Volunteer opportunities are an excellent way to gain experience. Many zoos and aquariums have active volunteer programs. Employment in a pet store is another possible means of gaining entry-level experience in the care of aquatic animals.

\section{Careers that Usually Require a Master's Degree}

Because aquatic animal health is a highly specialized field, and the dynamics of the aquatic environment are key to the health and well-being of the animals that live there, many careers require education to the master's level. A master's degree

1. This document is VM146, one of a series of the Large Animal Clinical Sciences Department, Florida Cooperative Extension Service, Institute of Food and Agricultural Sciences, University of Florida. Original publication date January, 2004. Visit the EDIS Web Site at http://edis.ifas.ufl.edu.

2. Ruth Francis-Floyd, Professor, Fisheries and Aquatic Sciences, Cooperative Extension Service, Institute of Food and Agricultural Sciences, University of Florida, Gainesville, 32611.

The Institute of Food and Agricultural Sciences (IFAS) is an Equal Opportunity Institution authorized to provide research, educational information and other services only to individuals and institutions that function with non-discrimination with respect to race, creed, color, religion, age, disability, sex, sexual orientation, marital status, national origin, political opinions or affiliations. U.S. Department of Agriculture, Cooperative Extension Service, University of Florida, IFAS, Florida A. \& M. University Cooperative Extension Program, and Boards of County Commissioners Cooperating. Larry Arrington, Dean 
generally involves two years of advanced course work (after completion of a bachelor's degree) in an area of interest to the student. There are two general types of master's degrees, thesis and non-thesis. A degree requiring a thesis is a research degree in which the student must conduct original research under the supervision of a major professor and committee and then write a detailed scientific paper (thesis) on the research. A non-thesis degree involves advanced course work but a research paper may be substituted for the thesis. A non-thesis degree is not recommended if the individual's dream job would include a research component. Students who have completed a master's degree will usually meet the minimum requirements for a career as a biologist with a state or federal agency. They might also be qualified to work in a supervisory capacity on an aquaculture farm, work as a county extension agent or go into teaching. Some of these jobs (ie. county extension agent) may only require a bachelor's degree for an entry-level position but would then expect (require) the person to complete his or her master's degree while on the job.

\section{Careers that Require a Veterinary Degree}

Veterinary medicine is a medical degree. Most veterinary schools, including the University of Florida, offer the "DVM" or "Doctor of Veterinary Medicine" degree. The course work in veterinary school is intensive and there is relatively little flexibility in the curriculum for specialized training in an area of interest. As mentioned above, aquatic animal medicine is highly specialized. There are only a few hundred veterinarians worldwide who work in aquatic medicine full-time, but the number is increasing rapidly as aquatic industries mature and expand. There are also veterinarians who incorporate a component of aquatic medicine into their practices. These include small animal veterinarians who see the occasional fish in their clinic. Koi practice, as a component of companion animal practice, is growing, and this is an area that offers significant opportunity for private practitioners to work with aquatic animals.

If your interest is working as a veterinarian with aquatic animals, your first goal has to be getting accepted into veterinary school. There are 24 veterinary schools in the United States and 4 in Canada. Each will have slightly different pre-requisites and program strengths. Although it is helpful to attend a school with a recognized program in aquatic animal medicine, such as the University of Florida, it is not essential. Elective courses in aquatic medicine are generally open to students from other institutions and there is a significant exchange of students between institutions. It is also helpful to take some undergraduate courses, or even graduate level courses, in aquatic or marine biology and related areas, but the overriding priority is to put together a competitive application to veterinary school.

Acceptance to veterinary school is very competitive and successful applicants generally have strong academic credentials as well as practical experience working with veterinarians.

Complete specialization in aquatic medicine often requires training beyond veterinary school. There are internships offered by several institutions. An internship is usually one year of intensive clinical experience with a significant amount of supervision by an experienced clinician. Internships may be offered by universities, zoos, aquaria, or private companies. Three veterinary colleges (North Carolina, California, and Florida) currently offer, residency programs in aquatic animal medicine. Residency programs are very intensive, generally follow an internship and several years of clinical practice, and last from 2 to 4 years, with the average being 3 years. They are highly competitive and generally offer the finest training and breadth of experience possible in a given field of study. Residency programs in aquatic animal medicine are approved by the American College of Zoological Medicine (ACZM). For graduates to receive board certification they must first fulfill credentialing requirements that allow them to take the ACZM examination. Then they must successfully pass a comprehensive two-day examination.

Because there are few internships and residency programs available in aquatic animal medicine and most of these are fairly new, another means of gaining experience and training in the field is graduate school. A master's degree after veterinary school provides advanced course work and an 
opportunity to conduct a research project. A PhD

(Doctor of Philosophy) degree is a very advanced research degree and is discussed briefly below.

\section{Careers Requiring a PhD Degree}

A PhD, or "Doctor of Philosophy" degree is a very advanced degree in which a tremendous amount of study and research is focused in one fairly small area. It usually takes at least four years to complete a $\mathrm{PhD}$ program. The first two years often consist of coursework in the student's chosen discipline. Examples of areas of study could include nutrition, microbiology or pathology. The student then spends approximately two years involved in original research under the supervision of a major advisor and an advisory committee. The research is then presented as a dissertation, and usually several scientific papers are published from the contents of the dissertation. Students who successfully complete their PhD degrees often spend their scientific careers working in academia, for a government agency, or for a private company. Some zoos and aquariums also employ full-time scientists.

\section{Summary}

Twenty years ago, a career in aquatic animal medicine was not considered a realistic goal because there were so few opportunities. Growth of aquaculture industries, public aquaria, public concern for environmental degradation, use of aquatic organisms in research, and the increased value of aquatic pets, have all resulted in a plethora of new career possibilities in this growing and exciting field. Opportunities are increasing every day, however the best trained, most experienced, and most persistent candidates usually get the best jobs. This is not a career path for those easily deterred. 